\title{
What factors impact on primary school students' online engagement for learning and entertainment at home
}

\author{
Jingyan Lu • Qiang Hao
}

Received: 28 April 2014/Revised: 12 June 2014/Accepted: 15 June 2014 /

Published online: 5 July 2014

(C) Beijing Normal University 2014

\begin{abstract}
Informed by the difference of children's Internet use in formal and informal contexts, this study aims to move away from studying children's more predictable Internet use in school settings to learning how children use the Internet at home, and what factors impact their online behavior in such contexts. Students from grade 3 to 6 from a school in a medium-sized city in China participated in the study. The data reveal that children use the Internet for both entertainment and learning purposes and these two factors are correlated. However, factors influencing Internet use for the two purposes are to some extent different. The study suggests that there is a need to zoom in and analyze children's Internet use in informal contexts, rather than assume that learning at home is just an extension of learning at school. Policy makers and educators may use information about how children use the Internet at home to improve pedagogy to bridge the gap between school and home.
\end{abstract}

Keywords Internet use - Primary students - Informal context - China · Online learning · Online entertainment

\section{Introduction}

With the increasing popularity and affordability of Information Communication Technology (ICT), children can now access the Internet from home via multiple

\footnotetext{
J. Lu ( $ه)$

Faculty of Education, The University of Hong Kong, Pokfulam Road, Pokfulam, Hong Kong e-mail: jingyan@hku.hk

Q. Hao

Learning, Design and Technology, The University of Georgia, Room 110, 850 College Station Road River Crossing, Athens, GA 30605, USA

e-mail: neohao@uga.edu
} 
devices, including desktop computers, laptops, and mobile devices. At the same time, improvements in formal and informal education have enabled young children to steadily improve their information literacy skills. It is no longer surprising to see primary school and even pre-school children using computers and mobile devices to play games, watch videos, or listen to music online. In developed countries, earlier concerns about a 'digital divide' among children due to inequalities in access to ICT have been replaced by concerns of ways in which they use it in school to learn (Bingimlas 2009; Webb 2005; Kerawalla and Crook 2002). However, school and home settings are constituted of different ecologies with different cultures (Stevenson 2011; Stephen et al. 2008), it is too soon to judge that one is inferior to the other and to assume that children should use ICT at home in a similar way as they use it in school.

Given the importance of ICT use at home, this study adopts an exploratory approach to investigate how primary school students in China use Internet at home and the individual and contextual factors that influence their online activities. School and home Internet use would not be compared as there is evidence that responses of students to using the Internet for lessons at school is becoming well established (Pelgrum 2008; Hayes 2007; Becta 2002). Policy makers, educators, and researchers have a more pressing need to better understand how and why students use the Internet outside school in order to bridge the gap between school and home learning environments and to leverage opportunities for inspiring students to learn in both settings.

\section{Background}

Using the Internet in non-school contexts

While earlier studies have shown that differences in the availability and use of ICT in schools are correlated with inequalities in family socio-economic status (SES), these differences have been narrowed down as ICT becomes less expensive and more popular in daily life. However, as concerns over an impending digital divide have waned, concerns over an emerging learning divide, i.e., differences in how children use ICT and new media to learn, have grown (OECD 2012). Given that how students use ICT in school is largely determined by their teachers, the types of media students use, and how and why they use them are to a certain extent predictable. Consequently, sources of this divide may be found in non-school settings.

Compared with the many studies focussing on how students use ICT in school settings, significantly fewer have focused on their use of ICT in non-school settings and most of these have focused on how students should use ICT and media at home (Rideout et al. 2010; Roberts et al. 2005). However, large variations have been found in how students use ICT outside school due to different kinds of factors. A number of individual factors, e.g., age, gender, and academic performance, and context factors, e.g., SES has been intensively investigated. Although a great deal of efforts has been directed to supporting Internet use of students at home, primary 
school students have received much less attention than their older counterparts. It could be assumed that the use of the Internet is less popular among younger children. This has been found to be the case in developed countries, such as the UK (Selwyn et al. 2009).

\section{Factors related to students' Internet use}

\section{Individual factors}

Most relevant studies have reported gender differences in Internet use. Many have identified a gender gap in computer use with boys generally spending more time on computers than girls. Due to this, boys have been found to have stronger computer skills and to be more motivated to get involved in computer-related activities than girls (Losh 2004; OECD 2007; Rideout et al. 2010). Further, boys and girls have been found to engage in different types of online activities. Boys spend more time playing computer games and watching online videos (Luckin et al. 2008; Rideout et al. 2010; Roberts et al. 2005), while girls spend more time participating in online social networks. Rideout et al. (2010) found that $95 \%$ of teenage girls participated several times a week in at least one online communication activity compared to $84 \%$ of teenage boys. Gender difference in online activities tends to increase among older teenagers (15-18 years) as opposed to their younger counterparts (9-14 years) (Lenhart et al. 2007). Despite the differences found in most studies, some studies report little or no gender differences in the online activities of boys and girls (Broos 2006; Livingstone and Bober 2004).

Age is the other factor influencing the online activities of students. Studies in the US and Europe have generally found that younger students (9-12 years) and older students (15-18 years) have different patterns of Internet use. Older students tend to spend more time on the Internet, and to engage in more types of online activities such as, watching video clips, chatting on Instant Message, or browsing news items than their younger counterparts (Lenhart et al. 2007; OECD 2012; Rideout et al. 2010; Roberts et al. 2005; Steeves 2005). Especially, online communication activities (e.g., visiting social network sites and chatting on Instant Message) have become more obviously popular as students enter adolescence (Livingstone et al. 2010).

Academic performance has always been a focal point of ICT studies as there has always been a concern that the more time students spend engaged in non-school related online activities, the less time they will have for study. This will in turn have a negative impact on their academic performance. The Kaiser Family Foundation has confirmed these concerns by reporting a negative relationship between nonschool Internet use and academic performance: heavy computer users generally have lower grades and lower levels of confidence (Rideout et al. 2010; Roberts et al. 2005). Wainer et al. (2008) found that this negative relationship was more evident among younger students (9-13 years) than among older ones (15-17 years. However, some studies report a positive relationship between ICT use and specific skills (O'Hara 2008; Subrahmanyam et al. 2000). Inconsistent findings concerning correlations between Internet use and academic performance could be due to 
different types of Internet use. Thus, to get a better understanding of Internet use and academic performance it would be useful to categorize online activities and examine relationships among those that are more relevant to academic performance.

\section{Context factors}

The context factors examined in this study include family social-economic status (SES; including family income and parental education) and offline home activities such as watching $\mathrm{TV}$, reading books, and communicating with other family members.

Family income is assumed to be related to home Internet access. Livingstone and Bober (2004) found that $88 \%$ of middle class children had home Internet access, while only $61 \%$ of working class children did. However, as ICT devices have become more affordable, this gap has narrowed. OECD (2012) reported that in Europe more than $95 \%$ of teenagers have at least one Internet-connected device at home. While Internet access is no longer an issue for most people, one study (Wainer et al. 2008) found that in Brazil, low-SES children spent more time on the Internet than high-SES children. One explanation could be that families with lower income cannot afford the cost of their children participating in other extracurricular activities and thus the Internet is a feasible alternative.

Level of family education has also been found to be related to children's Internet use (Zhao 2009). Broos (2006) found that mothers' level of education was significantly related to the types of online activities (e.g., learning and social networking) of their adolescent daughters. Lenhart et al. (2007) reported that children from high-SES and well-educated families were more likely to try new Internet activities, such as downloading podcasts or contributing to video sharing sites.

It is generally believed that new and traditional media are in competition. When TV was introduced, parents and educators were worried that students would spend less time reading. Similar concerns were expressed when the Internet was introduced. Ten years ago, students spent more time watching TV than they did online (Livingstone and Bober 2004). Recent studies show that students spend more time on the Internet than watching TV (Lenhart et al. 2007; Rideout et al. 2010). However, this does not necessarily mean that teenagers will spend the time they used to spend watching TV surfing the Internet. According to the Kaiser Family Foundation, heavy Internet users reported that they spent the same amount of time watching TV as light Internet users (Rideout et al. 2010; Roberts et al. 2005). Similarly, it was thought that children would spend less time reading print material as they spent more time surfing the Internet. However, it has been found that heavy and light Internet users spend the same amount of time reading print material (Rideout et al. 2010).

A paradox of social-connected isolation exists for students using Internet (OECD 2008). The Internet has often been characterized as a "devil" that drives individuals to spend most of their time away from family and friends (Bargh and McKenna 2004). As ICT devices and Internet access become more popular among teenagers, concerns are growing that they may spend less time in face-to-face communication 
with family and friends. However, it has also been reported that as more students share videos or pictures on the new social media or communicate on social networks, they are opening new channels of communication with friends and people they do not know (OECD 2008).

Previous studies have provided valuable information on the influence of computer and Internet use on three types of activities: watching TV, reading books, and communicating with family and friends. However, the correlation between Internet use and the three types of activities has not been thoroughly explored. If Internet use does not necessarily displace these activities, may it merge with or stimulate them? Similar questions remain to be answered.

\section{Young children and Internet in China}

Since the beginning of the 21st century, ICT has achieved great progress in primary and secondary schools in China (Wang et al. 2005). Recently, China has identified the development of ICT in education as a major goal in its 2010-2020 plan for educational reform and development (Ministry of Education of China 2012). China's ICT policy is transforming its schools into digital campuses and ICT is being integrated into more and more classes. More Chinese students are integrating ICT and Internet into both their formal learning at school and their informal learning at home (Center of Preventing Youth Internet Addiction 2013). With the spread of ICT to everyday life, children are learning how to use the Internet at an earlier age. According to a 2011 national survey (Centre of Young Pioneers of China 2011), $82 \%$ of Chinese families with 10- to 17-year-old children had Internet access and $87.5 \%$ of Chinese families with younger children had Internet access. Students rated social interaction and entertainment as their primary reasons for going online, but they also said that the Internet made learning easier. Comparing this data with data from the US and Europe (Lenhart et al. 2007; Luckin et al. 2008), it could be seen that the Internet access gap between Chinese children and children from developed countries has narrowed significantly. However, there is little research investigating how Chinese children use the Internet at home and what factors impact their home online activities.

\section{Research questions}

This study investigates a number of individual and contextual factors that influence Internet use by primary school students at home. Thus, it is concerned with how these individual and context factors relate to students' different online activities at home. The study poses two questions:

(1) Whether and how individual and context factors are related to students' online learning activities at home?

(2) Whether and how individual and context factors are related to students' online entertainment activities at home? 


\section{Methods}

\section{Participants}

One public school in a medium-sized city in eastern China was selected as the sample for this study. More than $56 \%$ cities in China are medium sized (Editorial committee of annual report on development of small- and medium-sized cities in China 2010), so students from such a city are comparatively more representative of children receiving education in urban areas than their counterparts living in big or small cities. The selected school ranks among the best primary schools in the city's local ranking system. Surveys were sent to all students in grades 3 through 6.846 students (response rate $95.7 \%$ ) responded to the surveys.

Survey design

We investigated how young students used Internet at home based on three Individual factors: Grade, Gender, and Academic Scores (average scores in mathematics and Chinese from the last semester), Offline Activities (including time on reading, watching TV, and communicating with family members), and context factors: SES (including parental education and family income).

As the lines between using different types of media/technology blur, it is becoming more complicated to differentiate, count, and categorize types of media used (e.g., students watch TV programs on mobile phones rather than on TV). Thus, it is difficult to clearly describe what students do by specifying the devices they use. Consequently, we categorized what they used Internet for, such as looking for information, reading news, watching videos, no matter what device they used e.g., computer, mobile phone, or tablet. The survey consisted of seven items which are divided into two categories, one about using the Internet for learning and the other about using the Internet for social and entertainment purposes (See Appendix 1 for the Survey).

The seven items were designed with four point Likert-scale formats in which never, occasionally, sometimes, and often were assigned to $0,1,2$, and 3 , respectively. Exploratory factor analysis indicates all items have high loadings on the two factors (Table 1). Confirmatory factor analysis was run to test if the twocategory model is fit: CFI is .97 and RMSEA is .045, which prove good model fit. The Cronbach alpha for the Learning and Entertainment subscale are 0.56 and 0.76 , respectively.

Data sources and data analysis

Two types of data were collected for data analysis: (1) Exam scores (mathematics and Chinese scores) from the previous semester and (2) Survey data including individual and context factors, and items on how students use Internet. Students were asked to answer the survey items together with their parents. Since exam items differed for different grades, raw scores were transformed into standardized $Z$ scores. Averages were calculated on mathematics and Chinese scores to represent 
Table 1 Exploratory factor analysis on the seven items on using Internet at home

\begin{tabular}{lll}
\hline Items & Factor 1 & Factor \\
\hline Factor 1: Internet_Entertainment & & \\
1. Multimedia & .70 & \\
2. Game & .69 & \\
3. Chatting & .77 & \\
4. SNS & .73 & .74 \\
Factor 2: Internet_Learning & & .72 \\
1. SNS & & .60 \\
2. Homework & & \\
3. Seek_Info & &
\end{tabular}

Internet_Entertainment Using Internet for entertaining, Multimedia Viewing or downloading music, videos, photos, or pictures, Game Playing games online, Chatting Chatting with friends online, SNS Visiting social network website, Internet_Learning Using Internet for learning, Discuss Communicating online with classmates on learning, Homework Writing homework or report online, Seek_Info Searching information online for school work

the academic performance of students. For survey items, averages were calculated on the items in two categories each and transformed into two new variables: Using Internet for learning and Using Internet for Entertainment.

Independent variables are context factors and individual factors. Context factors included education levels of father and mother, and family income. Individual factors included gender, grade, academic performance, and time spent reading books, watching TV, and communicating with parents. Hierarchical multiple regression was used to examine the relationship between context and individual factors with two dependent variables, respectively: using Internet for learning and using Internet for entertainment. The context factors were entered into the regression model in the first step and the individual factors were entered in the second step. The purpose is to differentiate the prediction of the two types of factors.

\section{Results}

Descriptive analysis

Data from 846 students were collected and 36 of them were excluded from analysis due to missing major information in the survey. Among all students, $40.3 \%$ were girls and $59.7 \%$ were boys.

Table 2 gives a descriptive summary of all survey items. It can be seen that the average family annual income of most students is between RMB 20,000 and RMB 50,000 (Mean = 2.52). The fathers and mothers of most students had high school degrees [Mean (father) $=3.13$, Mean (mother) $=2.87$ ]. With respect to traditional activities at home, most students invested about the same amount of time in reading $($ Mean $=2.58)$ and communicating with parents (Mean $=2.50)$, but relatively less time on watching TV $($ Mean $=1.69)$. For activities relevant to Internet use, students 
Table 2 Descriptive analysis on the items in the survey

\begin{tabular}{|c|c|c|c|c|c|c|c|}
\hline & Range & Min & Max & Mean & SD & Skewness & Kurtosis \\
\hline Exam_Score & 88.50 & 11.00 & 99.50 & 83.96 & 13.72 & -1.69 & 3.92 \\
\hline \multicolumn{8}{|l|}{ Individual factors } \\
\hline Time_TV & 3 & 1 & 4 & 1.69 & 0.88 & 1.21 & 0.68 \\
\hline Time_Commu & 4 & 1 & 5 & 2.50 & 1.20 & 0.71 & -0.32 \\
\hline Time_Read & 4 & 1 & 5 & 2.58 & 0.97 & 0.90 & 0.37 \\
\hline \multicolumn{8}{|l|}{ Context factors } \\
\hline Edu_Father & 5 & 1 & 6 & 3.13 & 1.17 & 0.21 & -0.59 \\
\hline Edu_Mother & 5 & 1 & 6 & 2.87 & 1.18 & 0.36 & -0.46 \\
\hline Income & 5 & 1 & 6 & 2.52 & 1.15 & 0.84 & 0.64 \\
\hline \multicolumn{8}{|l|}{ Online activities } \\
\hline Factor 1: Internet_Entertainment & 3 & 0 & 3 & 1.22 & 0.79 & 0.40 & -0.71 \\
\hline Multimedia & 3 & 0 & 3 & 1.29 & 1.12 & 0.29 & -1.27 \\
\hline Game & 3 & 0 & 3 & 1.61 & 0.92 & 0.04 & -0.90 \\
\hline Chat & 3 & 0 & 3 & 1.27 & 1.13 & 0.27 & -1.34 \\
\hline SNS & 3 & 0 & 3 & 0.68 & 0.93 & 1.15 & -0.21 \\
\hline Factor 2: Internet_Learning & 3 & 0 & 3 & 1.63 & 0.64 & -0.14 & -0.39 \\
\hline Discuss & 3 & 0 & 3 & 1.41 & 0.94 & 0.08 & -0.90 \\
\hline Homework & 3 & 0 & 3 & 1.42 & 1.07 & 0.10 & -1.24 \\
\hline Seek_Info & 3 & 0 & 3 & 2.07 & 0.81 & -0.51 & -0.37 \\
\hline
\end{tabular}

Exam_Score Average of math and Chinese exam scores, Time_TV Time spent on watching TV per day, Time_Commu Time spent on communication with families per day, Edu_Father Education level of the father, Edu_Mother Education level of the mother, Income Annual family income. (Refer to Appendix about coding rules)

generally reported that they used Internet more frequently for learning (Mean $=1.63)$ than for entertainment $($ Mean $=1.22)$. They used networks more often to seek information (Mean $=2.07$ ) relevant to learning than to other online activities. Students reported that they rarely visited social network communities (Mean $=0.68)$. There were no significant differences in network engagement for other purposes. Table 3 shows the correlations among major variables. Using Internet for learning and entertainment has significant positive correlation $(r=.19$, $p<.01)$.

\section{Multiple regression}

Multiple regression analyses were run to examine the impact of independent variables on the two dependent variables-using Internet for learning and using internet for entertainment, respectively.

In the regression model predicting Using internet for learning, all independent variables accounted for about $11 \%$ of variance. The context factors were significant predictors $\left(R^{2}=.027, p<.01\right)$, among which mother's level of education was the only significant predictor $(t=2.52, p<.01)$. When students' personal information 
Table 3 Zero-order correlations among major variables $(N=849)$

\begin{tabular}{|c|c|c|c|c|c|c|c|c|c|}
\hline & 1 & 2 & 3 & 4 & 5 & 6 & 7 & 8 & 9 \\
\hline \multicolumn{10}{|l|}{ 1. Exam_score } \\
\hline 2. Grade & -.00 & & & & & & & & \\
\hline 3. Time_TV & $-.16^{* *}$ & $.16^{* *}$ & & & & & & & \\
\hline 4. Time_Commu & $.08 * *$ & .03 & .01 & & & & & & \\
\hline 5. Time_Read & $.14 * *$ & $.14 * *$ & $-.08 *$ & $.19 * *$ & & & & & \\
\hline 6. Edu_Father & $.33^{* * *}$ & $.09 *$ & $-.11 * *$ & $.16^{* * *}$ & $.16^{* *}$ & & & & \\
\hline 7. Edu_Mother & $.34 * *$ & $.08 * *$ & $-.10^{* *}$ & $.17 * *$ & $.15^{-}$ & $.69 * *$ & & & \\
\hline 8. Income & .07 & $.14^{* *}$ & .025 & .03 & .04 & $.12 * *$ & $.16^{* *}$ & & \\
\hline 9. Internet_Learning & $.16^{* *}$ & $.24 * *$ & $-.08 * *$ & $.11 * *$ & $.17 * *$ & $.10 * *$ & $.14^{* *}$ & .06 & \\
\hline $\begin{array}{l}10 . \\
\text { Internet_Entertainment }\end{array}$ & -.05 & $.45^{* *}$ & $.28 * *$ & .04 & .05 & -.02 & .00 & $.16^{* *}$ & $.19 * *$ \\
\hline
\end{tabular}

Grade the grade a student is in

$* * p<0.01$

was added to the model, there was a significant change of variance (adjusted $\left.\Delta R^{2}=.083, p<.001\right)$. Exam scores $(t=2.52, p<.05)$, Time spent reading $(t=2.57, p<.05)$, Grade level $(t=6.03, p<.001)$, and Time spent watching TV $(t=-2.36, t<.05)$ were significant predictors for Using internet for learning (Table 4).

In the regression model predicting Using internet for entertaining, all independent variables accounted for about $28 \%$ of variance. The context factors were significant predictors $\left(R^{2}=.024, p<.001\right)$. Unlike the model predicting Using internet for learning, family income $(t=3.97, p<.001)$ was the significant predictor. When individual factors were added to the model, family income factor remained and there was a significant change of variance (adjusted $\Delta R^{2}=.258$, $p<.001)$. Time spent watching TV $(t=5.39, p<.001)$, Grade level $(t=11.27$, $p<.001)$, and Gender $(t=-5.55, p<.001)$ were significant predictors for Using internet for entertaining (Table 5).

\section{Discussion}

This study explored the factors and patterns of factors explaining home Internet use for learning and entertainment by primary school students in China. Results showed that home Internet use for these two purposes was related but there were major differences in patterns of factors predicting the two.

Online learning and entertainment at home: connections

Both context and personal factors have a significant impact on children using Internet for learning and entertainment though different predictors were found to have effects on learning and entertainment. Using the Internet for learning and 
Table 4 Multiple regression analysis in predicting Using internet for learning

\begin{tabular}{|c|c|c|c|c|c|c|}
\hline & $R^{2}$ & $R_{\mathrm{adj}}^{2}$ & $\Delta R^{2}$ & $\Delta F$ & $\beta$ & $t$ \\
\hline Step 1 & .027 & .022 & $.027 * * *$ & 6.04 & & \\
\hline Edu_Father & & & & & .02 & -.36 \\
\hline Edu_Mother & & & & & $.13 *$ & 2.53 \\
\hline Income & & & & & .05 & 1.26 \\
\hline Step 2 & .11 & .098 & $.083 * * *$ & 10.21 & & \\
\hline Edu_Father & & & & & -.04 & -.74 \\
\hline Edu_Mother & & & & & .10 & 1.84 \\
\hline Income & & & & & .02 & .50 \\
\hline Gender & & & & & .03 & .74 \\
\hline Grade & & & & & $.23 * * *$ & 6.03 \\
\hline Exam_score & & & & & $.10 *$ & 2.52 \\
\hline Time_TV & & & & & $-.09 *$ & -2.36 \\
\hline Time_Commu & & & & & .04 & 1.05 \\
\hline Time_Read & & & & & $.10 *$ & 2.57 \\
\hline
\end{tabular}

$* p<.05 ; * * p<.01 ; * * * p<.001$

Table 5 Multiple regression analysis in predicting Using Internet for entertainment

\begin{tabular}{|c|c|c|c|c|c|c|}
\hline & $R^{2}$ & $R_{\mathrm{adj}}^{2}$ & $\Delta R^{2}$ & $\Delta F$ & $\beta$ & $t$ \\
\hline Step 1 & .024 & .02 & $.024 * *$ & 5.47 & & \\
\hline Edu_Father & & & & & -.05 & -.92 \\
\hline Edu_Mother & & & & & .01 & .12 \\
\hline Income & & & & & $.16^{* * *}$ & 3.97 \\
\hline Step 2 & .28 & .27 & $.258 * * *$ & 39.22 & & \\
\hline Edu_Father & & & & & -.04 & -.88 \\
\hline Edu_Mother & & & & & .00 & .09 \\
\hline Income & & & & & $.10^{* *}$ & 2.83 \\
\hline Gender & & & & & $-.19 * * *$ & -5.56 \\
\hline Grade & & & & & $.39 * * *$ & 11.27 \\
\hline Exam_score & & & & & .03 & .77 \\
\hline Time_TV & & & & & $.18 * * *$ & 5.39 \\
\hline Time_Commu & & & & & .04 & 1.08 \\
\hline Time_Read & & & & & .03 & .72 \\
\hline
\end{tabular}

$* p<0.05 ; * * p<0.01 ; * * * p<.001$

entertainment is positively correlated which implies that students who spent more time using the Internet to learn also tended to spend more time using Internet for entertainment or vice versa. This finding goes against the assumption that using Internet for learning and for entertainment competes with each other (Eynon and 
Malmberg 2011; Lee et al. 2005). It suggests that there might be a synergy between online learning and entertainment in informal contexts. More studies are needed to examine the connections between using Internet for learning and entertainment in informal context.

Age has been found to be a significant factor for both online learning and online entertainment. The finding that older students spend more time learning online is consistent with earlier studies on the effect of age but with details on how such change happens among primary school students (Lenhart et al. 2007; OECD 2012; Ofcom 2007). This positive correlation implies that students might be asked to use more media or the Internet to look for information or to communicate with classmates for school work as they move to a higher grade; or their increased information literacy skills gained with age enable them to use Internet to learn. Age is also the most significant factor in the entertainment model. Older students engage in more social interaction and entertainment activities. This is also consistent with most western survey findings on the effect of age (Lenhart et al. 2007; OECD 2012). Comparatively, age showed larger effects on entertainment than on learning. As students age, they will have more accessibility, motivation, and skills that enable them to socialize online. However, learning online seems to be only affected by age at a moderate level and this effect might be limited to the nature of school tasks. Thus, instructional design might want to borrow ideas from online entertainment, to motivate students and amplify the impact of learning.

Online learning and entertainment at home: different patterns

The two regression models are different in the other predictors except for age. In the model that explains how children use Internet for learning, five significant predictors accounted for $11 \%$ variance: the older students are (discussed earlier), the better their academic performance; the more time they spend on reading print material and the higher their mothers' education level, the more time they would invest in online learning; more time they put on TV, less time they invest on online learning.

(1) Time spent reading on print media and students' academic performances are found to be positively related to using networks for learning. Considering that students' academic performances are also positively correlated with time spent on print media (see Table 3), the possible explanation could be that students who performed academically better are more likely to develop the reading habit, and they tend to extend the learning behavior (e.g., reading books) to network use. The positive correlation between students' academic performance and time spent on print media was also identified by some literature (Rideout et al. 2010; Roberts et al. 2005). As for the reason why this correlation is limited to print media, it could be that media for knowledge acquisition in schools largely remains print, especially in developing countries.

(2) Mothers' education level is also found to be positively related to students' network use for learning, while fathers' is not. This result is consistent with most studies on parents' education in which mothers play a more important 
role in children's education than fathers (Beller 2009; Johnston et al. 2005; Korupp et al. 2002).

(3) Time on TV is negatively correlated with online learning. The more time students watch TV, the less time they spend on learning online. Thus, watching $\mathrm{TV}$ is a competitor for students using Internet for learning.

In the regression model (Table 5) explaining using Internet for entertaining, four significant predictors account for $28 \%$ of variance, which makes the model stronger than the one explaining using internet for learning. Except for the age effect, the other three factors in using Internet for entertainment model are different from the factors in using internet for learning model: gender, time spent on TV, and family income. Time spent on TV and family income is positively related with using Internet for entertainment.

(1) The finding that children from families with higher income spend more time online for entertainment is consistent with findings in the literature (Livingstone and Bober 2004; OECD 2012). Families with higher income could afford their children more devices with Internet access, and these children are more likely to have their own computers, laptops, or mobile phones, which allow them more time to explore or relax online.

(2) It is interesting to note that watching TV plays opposite roles in the two regression models. The more time students spend watching TV, the less inclined they are to using Internet for learning, but more possible for entertainment. Consistent with previous studies on the role of TV (Ofcom 2007; Rideout et al. 2010), this finding provides a new perspective on the role of the Internet and TV. TV is mainly an entertainment medium, while the Internet plays a more complex role even in the lives of primary school students: they go online not only for entertainment, but also for social interaction and learning.

(3) Gender is found to have a significant effect on using the Internet for entertainment. Boys use the Internet more intensively than girls for entertainment purposes. When the types of online activities are checked, boys are found to engage in all four types of entertainment activities, including consuming multimedia, playing games, chatting online, and visiting SNS. This finding is similar to the finding of Hasebrink and his colleagues (Hasebrink et al. 2011) in the UK, but goes against some previous studies (Lenhart et al. 2007; Livingstone et al. 2010; OECD 2012) in which gender was found to have little influence on teenagers' Internet use.

(4) Different from prior studies in US or Europe, parents' education does not have a significant effect on children's use of Internet for entertainment. This might be explained by the culture factor. Educated Chinese parents might focus on guiding their children to be more involved in learning activities, but somewhat neglect children's social or entertainment activities.

Although online learning and entertainment are correlated, they are predicted by different factors. Understanding what these factors are and how they are related with online learning and entertainment at home is of great value. For instance, academic 
performance and reading are found to be related with online learning but not to online entertainment, which implies that online learning might be an extension of offline learning, and online entertainment might not be blamed for children's poor academic performance.

Prior concerns about a digital divide (Livingstone and Bober 2004) caused by inequalities in SES, have more recently been replaced by concerns about a learning divide (Hasebrink et al. 2011; OECD 2012). This study found that family income has no impact on using Internet for learning, while parents' education does. However, family income has an impact on using the Internet for entertainment, while parental education does not. This difference implies that using the Internet at home involves different activities which should be scrutinized as they are predicted by different factors. Parents' education can teach children how to use the Internet for learning but not enough to guide them for socialization and entertainment. On the other hand, family income might ensure children access facilities for entertainment but not be helpful for learning.

TV time has been a major factor in most studies of the relationship between old and new media, but findings of these studies vary: some found that new media displaced the time of old ones (Subrahmanyam et al. 2000; Marketingcharts 2013), and some suggested that there is a combination effect between the two kinds of media (Ofcom 2007; Rideout et al. 2010). In our study, by differentiating the purpose of using Internet, we identified different relationships of the two activities with TV time. Using the Internet for learning competed with watching TV, while using Internet for entertaining has combination effect with watching TV. In recent years, as the boundary between old and new media blurs (Rideout et al. 2010; Subrahmanyam et al. 2000), more and more people are choosing watching videos or reading online, we might need new perspectives to interpret the relationship of new and old media.

It has been a concern that children might have less time for communicating with their parents as they spend more time online (OECD 2008). In this study, we did not find such a correlation, either in online learning or online entertainment.

Using Internet at home and at school: understanding and building connections

Although our study focuses on using the Internet at home, it was stimulated by studies comparing ICT use at school and at home (Grant 2011; Jewitt and Parashar 2011; Selwyn et al. 2009; Stevenson 2011; Kent and Facer 2004). We would also like to see whether our findings have implications for teaching and learning with ICT in school settings. For a long time, it has been assumed that use of ICT in the home should replicate or extend its use in school settings (Kerawalla and Crook 2002). However, most studies have identified discrepancies between school and home ICT use. Some researchers have thought that this might be due to inequalities in Internet access and thus, have implemented programs to reduce such differences so as to improve students' access and use ICT at home with the hope to improve their learning and motivation in general (Jewitt and Parashar 2011). However, some studies have also revealed cultural differences between home and school use of ICT and the tension between the expected and actual ICT use among students (Stevenson 
2011). This urges us to take a practical perspective or bottom-up method to study ICT use in the home, e.g., ICT use is multifaceted and determined by multiple factors, rather than take a confirmatory perspective that home ICT should be guided for learning or toward school-like activities.

Formal and informal learning are used to characterize the learning that usually happens in and out of school. When it refers to learning with ICT, it is difficult to differentiate between "formal" and "informal" as students might gain more experience in learning with ICT out of school context. Thus, to reinforce the disconnection between school and home ICT use or to overemphasize the model of school ICT use might create difficulty for communication between the two settings. Although students might spend much time using Internet for entertainment purposes, their report on the preference of specific tools (e.g., SNS) should be taken seriously by schools as what should be counted as effective use of technology for learning (Jewitt and Parashar 2011).

\section{Limitations}

All the sample students come from the same school due to resource limits of this study. Therefore, whether the findings could be generalized to a broader context needs further examination in future studies. Stratified sampling on a larger scale could be adopted in the future study (i.e., sampling from different schools in different cities).

Survey is the only tool used in this study to explore how students use Internet for learning and entertainment at home. The level of realism may be negatively affected since participants are studied outside of the context where they use Internet. Ethnographical research or field study could be employed to zoom into the students' online activities at home to explain the findings from current study.

\section{Conclusions}

Application of educational ICT in China is still in its early stage. Since 2000, the Chinese government has invested billions of dollars in setting up basic ICT infrastructures, using ICT to improve teaching and learning and in reducing inequalities between urban and rural schools. However, in light of the immense amount of time, money, and efforts that western countries have been investing in the ICT in education, China has a lot of catching up to do.

According to the data collected in this survey, inequalities of Internet access, at least in urban areas of China, is no longer a big problem. This implies that educational policy makers should shift their focus from basic ICT infrastructures' construction to the emerging learning divide.

The empirical data presented in this paper brings out the possibility that students' ICT use in informal contexts is an important contributor to the emerging learning divide, which necessitates further research in students' home ICT use in China. To 
connect to home learning and improve school learning efficiency, schools need to understand students' own preference and online activities.

The data also reveals that online entertainment is not necessarily a negative factor in improving students' learning. The boundary between online learning and entertainment is getting blurry, and it should be taken seriously whether borrowing elements in students' favored online entertainment would improve their learning efficiency. This field needs more research in future.

Besides, this study also leads to the understanding that in solving the learning divide problem, some factors should be given more attention than others. Family SES plays an important role in students' online activities. Comparatively, parents' education has a more significant influence in students' online learning, which indicates that further research focusing specifically on parents' education and students' online activities is needed. More exploration in improving students' online learning by educating parents is one of the future research directions.

\section{Appendix 1}

Survey on primary school students' Internet use activities (translated from Chinese)

1. What is your gender?
A. Male
B. Female

2. Which grade are you in?

3. What is your father's education level?
A. Primary school
B. Middle school
C. High school or equivalent
D. Minor bachelor degree

F. Master degree or above

E. Bachelor degree

4. What is your mother's education level?
A. Primary school
B. Middle school
C. High school or equivalent
D. Minor bachelor degree
E. Bachelor degree
F. Master degree or above

5. What is the average annual family income?
A. Less than $20,000 \mathrm{RMB}$
B. Between 20,000 and 50,000 RMB 

C. Between 50,000 and 100,000 RMB
D. Between 100,000 and 200,000 RMB
E. Between 200,000 and 500,000 RMB
F. More than 500,000 RMB

6. How much time do you spend on watching TV per day?
A. About $30 \mathrm{~min}$
B. About $1 \mathrm{~h}$
C. About $2 \mathrm{~h}$
D. About $3 \mathrm{~h}$

7. How much time do you spend on communication with your families?
A. Less than $10 \mathrm{~min}$
B. About $30 \mathrm{~min}$
C. About $1 \mathrm{~h}$
D. About $2 \mathrm{~h}$
E. About $3 \mathrm{~h}$

8. The following questions are about your Internet use behavior at home (using mobile devices are also considered). Please choose among the four options for each question:
A. Often
B. Sometimes
C. Occasionally
D. Never

(1) Do you discuss with your classmates on doing homework, or other things related to learning online?

(2) Do you use Internet to do your homework?

(3) Do you search for information or material related to learning online?

(4) Do you listen to music, watch movie, or view pictures online (Downloading music, movie, and pictures is also considered)?

(5) Do you play games online?

(6) Do you chat with friends online?

(7) Do you visit social network sites (e.g., Sina Microblog)?

\section{References}

Bargh, J. A., \& McKenna, K. Y. A. (2004). The internet and social life. Annual Review of Physiology, 55, $573-590$.

Becta. (2002). ImpaCT2: The impact of information and communication technologies on pupil learning and attainment. http://dera.ioe.ac.uk/1572/. Retrieved 8 July 2013

Beller, E. (2009). Bringing intergenerational social mobility research into the twenty-first century: Why mothers matter. American Sociological Review, 74, 507-528.

Bingimlas, K. A. (2009). Barriers to the successful integration of ICT in teaching and learning environments: A review of the literature. EURASIA Journal of Mathematics, Science and Technology Education, 5(3), 235-245. 
Broos, A. R. K. (2006). The digital divide in the playstation generation self efficiency, locus of control and ICT adoption among adolescents. POETICS, 34, 306-317.

Center of Preventing Youth Internet Addiction. (2013). Summary on 2012 blue book of Beijing primary and secondary students Internet use investigation. Primary and Secondary School Information Technology Education, 3, 10-16. (in Chinese).

Centre of Young Pioneers of China. (2011). Report of Chinese kids' use of internet and social media. from http://kid.qq.com/zt2012/weichengnian/index.htm (in Chinese). Retrieved 13 June 2013

Editorial Committee of Annual Report on Development of Small and Medium-Sized Cities in China. (2010). Annual report on development of small and medium-sized cities in China. Beijing: Social Science Academic Press.

Eynon, R., \& Malmberg, L.-E. (2011). A typology of young people's Internet use: Implications for education. Computers \& Education, 56(3), 585-595.

Grant, L. (2011). 'I'm a completely different person at home': Using digital technologies to connect learning between home and school. Journal of Computer Assisted learning, 27(4), 292-302.

Hasebrink, U., Görzig, A., Haddon, L., Kalmus, V., Livingstone, S., \& network, M. o. t. E. K. O. (2011). Patterns of risk and safety online. In-depth analyses from the EU Kids Online survey of 9-16 year olds and their parents in 25 countries. London: LSE EU Kids Online.

Hayes, D. N. (2007). ICT and learning: Lessons from Australian classrooms. Computers \& Education, 49(2), 385-395.

Jewitt, C., \& Parashar, U. (2011). Technology and learning at home: findings from the evaluation of the Home Access Programme pilot. Journal of Computer Assisted learning, 27(4), 303-313.

Johnston, A., Ganzeboom, H., \& Treiman, D. (2005). mothers' and fathers' influences on educational attainment. Paper presented at the RC28 conference, Oslo.

Kent, N., \& Facer, K. (2004). Different worlds? A comparison of young people's home and school ICT use. Journal of Computer Assisted learning, 20(6), 440-455.

Kerawalla, L., \& Crook, C. (2002). Children's computer use at home and school: Context and continuity. British Educational Research Journal, 28(6), 751-771.

Korupp, S., Ganzeboom, H., \& Van Der Lippe, T. (2002). Do mothers matter? A comparison of models of the influence of mothers' and fathers' educational and occupational status on children's educational attainment. Quality \& Quantity, 36, 17-42.

Lee, M. K. O., Cheung, C. M. K., \& Chen, Z. (2005). Acceptance of Internet-based learning medium: The role of extrinsic and intrinsic motivation. Information \& Management, 42, 1095-1104.

Lenhart, A., Madden, M., Macgill, A. R., \& Smith, A. (2007). Teens and social media the use of social media gains a greater foothold in teen life as they embrace the conversational nature of interactive online media. Washington, DC: Pew/Internet.

Livingstone, S., \& Bober, M. (2004). UK children go online: Surveying the experiences of young people and their parents. London: London School of Economics and Political Science. http://www.childrengo-online.net. Retrieved 10 May 2013

Livingstone, S., Haddo, L., Görzig, A., \& Ólafsson, K. (2010). Risks and safety on the internet: The perspective of European children. London: LSE, EU Kids Online.

Losh, S. C. (2004). Gender, educational, and occupational digital gaps. Social Science Computer Review, 22(2), 152-166.

Luckin, R., Clark, W., Graber, R., Logan, K., Mee, A., \& Oliver, M. (2008). Learners' use of Web 2.0 technologies in and out of school in Key Stages 3 and 4.

MarketingCharts. (2013). Are young people watching less tv? (Updated-Q1 2013 Data). Available from MarketCharts. http://www.marketingcharts.com/wp/television/are-young-people-watching-less-tv24817/. Retrieved 9 July 2013.

Ministry of Education of China. (2012). 2011-2020 mid-to-long plan for educational reform. http://www. moe.gov.cn/ewebeditor/uploadfile/2012/03/29/20120329140800968.doc (in Chinese). Retrieved 14 June 2012

O'Hara, M. (2008). Young children, learning and ICT: A case study in the UK maintained sector. Technology, Pedagogy and Education, 17(1), 29-40.

OECD. (2007). PISA 2006: science competencies for tomorrow's world, volume I analysis. Paris: OECD.

OECD. (2008). New millennium learners. Initial findings on the effects of digital technologies on schoolage learners. Paper presented at the OECD/CERI International Conference "Learning in the 21st Century: Research, Innovation and Policy". Paris: OECD.

OECD. (2012). Connected minds: Technology and today's learners, educational research and innovation. Paris: OECD. 
Ofcom. (2007). Ofcom's submission to the Byron review. Annex 5: The evidence base-the views of children, young people and parents. London: Office of Communications.

Pelgrum, W. J. (2008). School practices and conditions for pedagogy and ICT. In N. Law, W. J. Pelgrum, $\&$ T. Plomp, (Eds.). Pedagogy and ICT use in schools around the world: Findings from the IEA SITES 2006 study (Vol. 23) (pp. 67-120). Hong Kong: Comparative Education Research Centre, The University of Hong Kong, and Dordrecht: Springer.

Rideout, V. J., Foehr, U. G., \& Roberts, D. F. (2010). GENERATION M2: Media in the lives of 8-to 18-year-olds. Menlo Park, CA: Henry J.: Kaiser Family Foundation.

Roberts, D. F., Foehr, U. G., \& Rideout, V. (2005). Generation M: Media in the lives of 8-18 year-olds. Menlo Park, CA: Henry J.: Kaiser Family Foundation.

Selwyn, N., Potter, J., \& Cranmer, S. (2009). Primary pupils' use of information and communication technologies at school and home. British Journal of Educational Technology, 40(5), 919-932.

Steeves, V. (2005). Young Canadians in a wired world phase II: Trends and recommendations. http://www. media-awareness.ca/english/research/YCWW/phaseII/upload/YCWWII\%5ftrends\%5frecomm.pdf. Retrieved 10 May 2013

Stephen, C., McPake, J., Plowman, L., \& Berch-Heyman, S. (2008). Learning from the children exploring preschool children's encounters with ICT at home. Journal of Early Childhood Research, 6(2), 99-117.

Stevenson, O. (2011). From public policy to family practices: Researching the everyday realities of families' technology use at home. Journal of Computer Assisted learning, 27(4), 336-346.

Subrahmanyam, K., Kraut, R. E., Greenfield, P. M., \& Gross, E. F. (2000). The impact of home computer use on children's activities and development. Children and Computer Technology, 10(2), 123-144.

Wainer, J., Dwyer, T., Dutra, R. S., Covic, A., Magalhaes, V. B., Ferreira, L. R. R., et al. (2008). Too much computer and Internet use is bad for your grades, especially if you are young and poor: Results from the 2001 Brazilian SAEB. Computers \& Education, 51(4), 1417-1429.

Wang, Z., Liu, Y., Huang, H., Zhao, G., \& Li, L. (2005). Surveys on construction and application of educational informalization in primary and secondary schools. GET China Educational Technology, 22, 25-32. (in Chinese).

Webb, M. E. (2005). Affordances of ICT in science learning: Implications for an integrated pedagogy. International Journal of Science Education, 27(6), 705-735.

Zhao, S. (2009). Parental education and children's online health information seeking: beyond the digital divide debate. Social Science and Medicine, 69(10), 1501-1505.

Jingyan Lu is now the assistant professor in the Division of Information and Technology Studies in the University of Hong Kong. Her major areas of research include Educational Technology, the Learning Sciences, and Educational Psychology with a focus on uncovering and facilitating human thinking and learning with information technology. She has published her research on various Journals including Instructional Science, Computers and Education, International Journal of Computer supported Collaborative learning, Interactive Learning Environments; Learning and Metacognition, etc. She is also the key member of University Strategic Research Theme in the Sciences of Learning.

Qiang Hao is currently a Ph.D. student in Learning, Design and Technology Program of University of Georgia. His interested research areas include Self-regulated Learning and Problem-based Learning in Internet-based environment. 